\title{
Z PLASTY- A TECHNIQUE FOR FRENECTOMY - A CASE REPORT
}

\section{Dr. Neeta V. Bhavsar}

\section{Dr. Dhara S. Jadav*}

Dr. Aysha A. Khatri
MDS, Professor and HOD, Department Of Periodontia Government Dental College And Hospital, Ahmedabad

Post Graduate, Department of periodontia, Government dental college and hospital, Ahmedabad *Corresponding Author

Post Graduate, Department of periodontia, Government dental college and hospital, Ahmedabad

ABSTRACT Maxillary labial and buccal frenum are considered as normal anatomic structures in the oral cavity. However, they may exist intraorally as a thick broad fibrous attachment and/or become located near the crest of the residual ridge, thus interfering with proper denture border extension resulting in inferior denture stability, retention and overall patient satisfaction. This case report highlights the importance of clinical examination and treatment planning which may mandate pre prosthetic surgery prior to fabrication of a new conventional partial denture. Adequate patient satisfaction with conventional partial dentures can be significantly increased after frenectomy.

\section{KEYWORDS : z plasty, frenectomy, pre prosthetic surgery.}

Introduction

Esthetic concerns have led to an increased demand in seeking dental treatment for achieving perfect smile. The frenum is a mucous membrane fold that attaches the lip and the cheek to the alveolar mucosa, the gingiva, and the underlying periosteum. Oral cavity exhibits most notably the maxillary labial frenum, the mandibular labial frenum, and the lingual frenum. Labial frenum attachments are thin folds of mucous membrane containing muscle fibers originating from orbicularis oris muscle of upper lip which provides attachment to the alveolar mucosa and underlying periosteum.

The labial frenal attachments have been classified as mucosal, gingival, papillary and papilla penetrating, by Placek et al (1974)

Mucosal - when the frenal fibres are attached up to the mucogingival junction.

Gingival - when the fibres are inserted within the attached gingiva.

Papillary - when the fibres are extending into the interdental papilla.

Papilla penetrating - when the frenal fibres cross the alveolar process and extend up to the palatine papilla.

When the two central incisors erupt widely separated, no bone is deposited inferior to the frenum. This leads to a V-shaped bony cleft formation between the two central incisors and an aberrant frenum attachment. It is composed of attachment of thin fibrous tissue connecting the upper lip to the gingival tissue between the central incisors. The maxillary frenum provides stability to the upper lip. ${ }^{3}$ The mandibular frenum is considered anomalous when it is associated with a decreased vestibular depth and an inadequate attached gingival width. When there is a thick fibrous tissue attachment between the upper incisors, it results in the formation of hyperplastic frenum and is often associated with a midline diastema, gingival ressesion,speech problem and other periodontal problem. The abnormal frenal attachment can be detected visually by applying tension over the frenum to see the movement of the papillary tip or blanching of the associated area because of the resulting ischemia in the region.

Management of aberrant frenum- The management of an aberrant frenum can be accomplished by "frenectomy" or "frenotomy" procedures. The terms frenectomy and frenotomy signify operations that differ in degree of surgical approach. Frenectomy is a complete removal of the frenum, including its attachment to the underlying bone whereas frenotomy involves relocation of the frenal attachment. ${ }^{4}$

\section{Case report}

We report here a case of a $45 y$ year-old male referred to the Department of Periodontology., Government Dental College and Hospital, Ahmedabad. Patient reported with shallow vestibule. On examination, a hypertrophied papillary frenum. Tention test found positive. Patient was told about the procedure and an informed consent was taken. Technique is indicated when there is hypertrophy of the frenum with a low insertion ,also in cases of a shallow vestibule. Z-plasty is a plastic surgery technique used to improve the functional and cosmetic appearance of scars. It involves a central incision and creation of two triangular flaps of equal dimension that are then transposed and sutured.

Fig.l pre operative front view

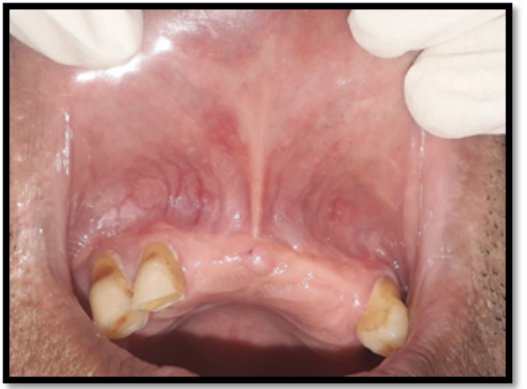

Fig. 2 pre operative lateral view

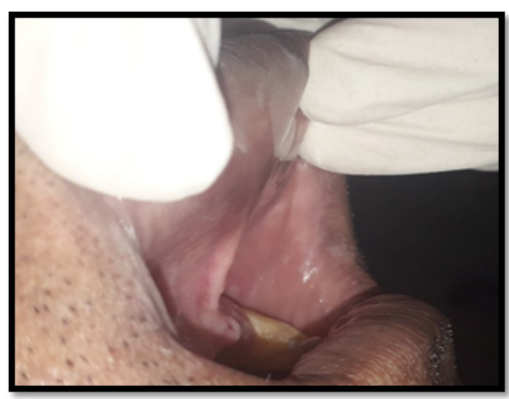


Fig. 3 vertical incision

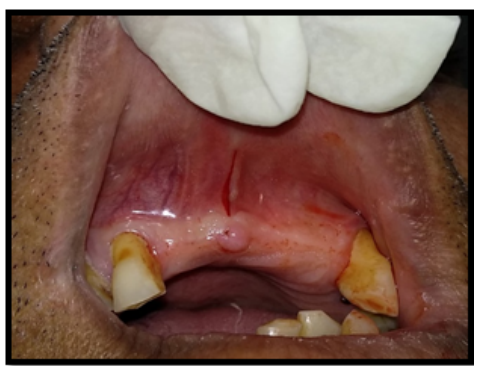

Fig.4 measurement of $10 \mathrm{~mm}$ incision at $60^{\circ}$, upper and lower end of vertical incision

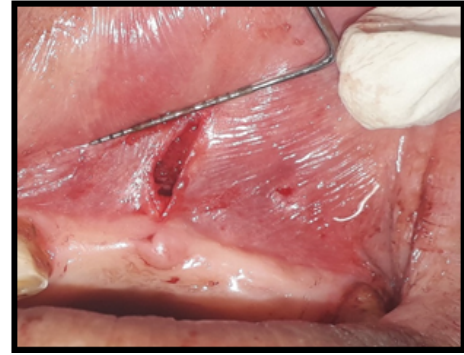

Fig. 5 partial thickness flap

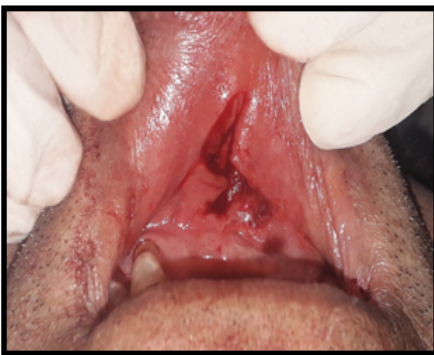

Fig.6 falp transposition

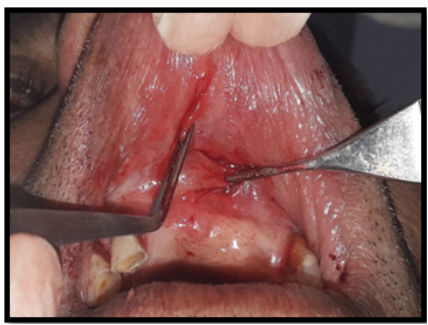

Fig. 7 suture placed

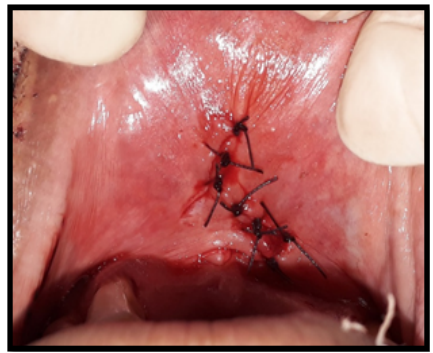

Fig. 8 after 7 days

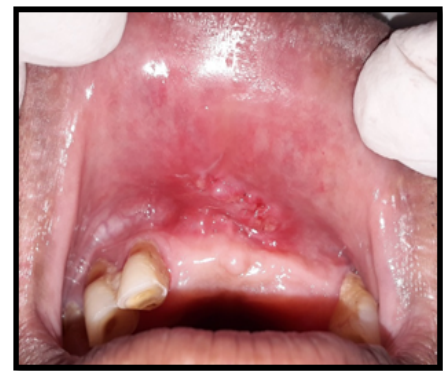

Fig. 9 after 1 month

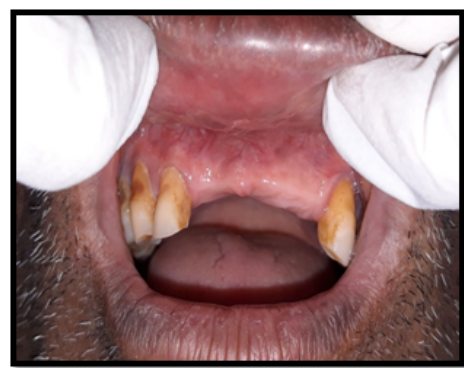

Fig. 10 prosthesis given

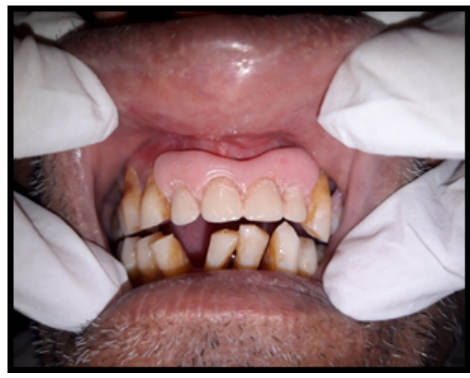

\section{DISCUSSION}

A frenum can become a significant problem if tension from lip movement pulls the gingival margin away from the tooth, or if the tissue inhibits the closure of a diastema during orthodontic treatment. 4 Various frenectomy procedures have been introduced so far. These include the classical technique, Millers technique, V-plasty, Y-plasty, Z-plasty, electrocautery and laser. The classical technique leaves a longitudinal surgical incision and scarring, which may lead to periodontal problems and an unaesthetic appearance, thereby necessitating the application of other procedures. Electrocautery and laser are mostly beneficial in patients with bleeding disorders and in patients who are apprehensive to blood. ${ }^{5}$

The $\mathrm{Z}$ pattern is effective as it promotes the redistribution of tension on the skin and the wound and helps in healing along the skin lines. It helps in minimising scar formation and has a camouflaging effect._ Basic Z-plasty flaps are created using an angle of $60^{\circ}$ on each side. ${ }^{6}$. Classic $60^{\circ}$ Z-plasty lengthens scars by $75 \%$, while $45^{\circ}$ and $30^{\circ}$ designs lengthen scars by $50 \%$ and $25 \%$, respectively. Hence, $60^{\circ}$ Z-plasty was performed here for better results.

During the implant era, preprosthetic surgery has been overlooked by many dentist and whenever improvement of denture retention and stability is needed, it is normally achieved by dental implants. ${ }^{7}$ However, dentist should keep in mind the following: 1) not every patient can afford implant therapy, especially elderly patients due to limited economic status; 2) preprosthetic surgery alone can sometimes be enough for improvement of denture retention and stability; and 3) Hillerup6 has stated that "many clinical conditions, especially in the maxilla, cannot be managed solely with implants. The combination of preprosthetic surgery and implants may solve problems that either discipline cannot solve alone". This clinical report supports that preprosthetic surgery is sometimes helpful for enhancement of future complete dentures, thus preventing patients from going through a more expensive and time-consuming treatment with dental implants. ${ }^{8}$

The main advantage of the Z-plasty method over the conventional technique is minimal scar tissue formation and permits better redistribution of scar contracture lines. The disadvantage of this method is its technique sensitivity. 
CONCLUSION

To achieve a functional and an esthetic outcome, adequate technique should be selected based on the type of the frenal attachment. The Z-frenuloplasty procedure is considered to be safe and a cost efficient procedure resulting in better functional and esthetic appearance. This technique allows for tissue healing by primary intentions, increasing recovery and reducing the risk of tissue contractures. However, due to the limited evidence currently available on this method, further research is needed to compare the different surgical approaches of frenectomy to obtain the desired outcome.

\section{REFERENCES}

1) Devishree SK, Gujjari SK, Shubhashini PV. Frenectomy: A review with the reports of surgical techniques. J Clin Diagn Res 2012;6:1587-92

2) Placek M, Miroslavs, Mrklas L. Significance Of The Labial Frenal Attachment In Periodontal Disease In Man. Part 1; Classification And Epidemiology Of The Labial Frenum Attachment. J Periodontol 1974:45:891- 894.

3) Jolly Sinha, Vivek Kumar, Amitandra Kumar Tripathi, Charanjit Singh Saimbi, Untangle lip through Z-plasty. BMJ Case Rep 2014

4) Gurpreet Kaur, Sujata Malik, Deepak Grover, Anupriya Sharma, Surgical Management of Aberrant Labial Frenum Using Modified Z-Frenuloplasty, IJSS Case Reports \& Reviews | March 2015 | Vol 1 | Issue 10

5) Priyanka M, Sruthi $R$, Ramakrishnan $T$, et al. An overview of frenal attachments. J Ind Soc Periodontol 2013;17:12-15

6) Salam OA, Amin JP. Michigan State University College of Human Medicine, East Lansing, Michigan. Am Fam Physician 2003;67:2329-32

7) Hillerup S. Preprosthetic surgery in the elderly. J Prosthet Dent. 1994;72:551-558

8) Frenectomy for improvement of a problematic conventional maxillary complete denture in an elderly patient: a case report. Youssef S. Al Jabbari, J Adv Prosthodont. 2011 Dec; 3(4): 236-239. 